The only plant successively inoculated was Nicotiana tabacum var. White Burley.

The mycelium was present on both surfaces of the leaves, but it was usually more abundant on one side than the other. In the greenhouse and trial plots near by, the upper surface was most commonly infected, while in the fleld the mycelium was more prevalent on the lower surface. Round to oval patches, about 1-3 cm. in diameter, were formed, and on severely infected leaves these coalesced. The affected areas were at first pale green, but afterwards developed a powdery-white appearance. In no case were the petioles or stems powdery-white appearanced K $_{\text {unkel }}^{2}$.

The haustoria, which were formed in the epidermal cells, were subglobose to ovate in shape, measuring approximately $41.5 \mu$ by $27.5 \mu$. The mean dimensions of the conidia were $29 \cdot 6 \mu$ by $16 \cdot 8 \mu$. No perithecia were perithecia were formed on infected leaves, but

and is generally accepted that this mildew belongs to Erysiphe It is generally accepted that this mildew belongs to Erysiphe cichoracearum, though it has not been proved. This species, however, was definitely recorded on potato plants in France in 1927. No other reports of a powdery mildew on potato plants have been recorded

I wish to acknowledge my indebtedness to Dr. W. A. R. Dillon Weston, who brought

School of Agriculture,

D. G. THOMAS

Cambridge.

1 Pethybridge, G. H., et al., Min. Agric. Bull. No. 79, 31 (1934).

2 Kunkel, L. O., Phytopath., 26, 4, 392 (1936). 153 (1921); eited in

Rev. Appl. Mycol., 1, 361 (1922).

Transmission of $L$. carinii to Laboratory Animals

Dr. F. Hawking and Miss A. M. Burroughs in a letter to Nature state that they have conflrmed the reports of the American workers, Williams and Brown ${ }^{2}$, and Scott (private communication), regarding the transmission of $L$. carinii to laboratory (piebald) rats, and that in addition they transferred the infection to hamsters and white mice. The establishment of a strain of flariasis in such a universally available laboratory animal as the white rat would be of great value to workers in tropical medicine, since it would provide them with the means of studying the effects of drugs on a disease heretofore regarded as incurable, and this problem has recently been studied by us at the as incurpool School of Tropical Medicine. The results of our investigations, which will be published in the next number of the Annals of Tropical Medicine and Parasitology, although conflrming the American workers' statement that $L$. carinii can be transmitted to white rats, do not support the view that a strain of $L$. carinii, suitable for chemodo not support thestigation, can be successfully maintained in these animals.

Our preliminary observations agreed with those of Dr. Hawking in confirming the American work, but on more intensive study, we observed that although transmission of $L$. carini $i$ from the cotton rat to the white rat could be successfully performed by means of the o the infective forms reached the adult vector, $L$. bacoti, and although the and produced microfilariæ, the adult stage, became sexually mature, and produced microflaria, the adult worms in the pleural cavity of the white rat were progressively encapsulated and died within as short a period as the days of the first exposure to infection. This premature death of the adult worm

never been observed by us in the natural host, the cotton rat.

In further experiments in which adult $L$. carinii were transferred by surgical means from the pleural cavities of cotton rats to those of white rats, microflariæa appeared in the peripheral blood of the latter some ten days afterwards, and persisted for a further three weeks, at the end of which period the animals were killed, and it was found that the parent worms were dead and in various stages of encapsulation. We have not attempted to infect white mice or hamsters, but the results of the experiments reported by Dr. Hawking and Miss Burroughs suggest that these animals may react in a similar manner to white rats, and that caution must be exercised before accepting the view that the presence of microflarim in the peripheral blood of these establish a permanent strain of filariasis for chemotherapeutic studies. D. S. BERTRAM K. UNSWORTH
R. M. GORDON

Department of Entomology and Parasitology, School of Tropical Medicine,

$$
\begin{aligned}
& \text { Pembroke Place } \\
& \text { Liverpool } 3 .
\end{aligned}
$$

1 Nature, 158, 98 (1946).

2 Williams, R. W., and Brown, H. W., Science, 102, 482 (1945) ; 103 , $224(1946)$.

\section{Polyploidy in Sainfoin}

AMONG the herbage crops, cocksfoot (Dactylis glomerata L.) ${ }^{1}$ and bird's foot trefoil (Lotus corniculatus L.) ${ }^{2}$ have been shown to be autotetraploids, and lucerne (Medicago sativa L.), having also given autotetraploids, and wich ean best be interpreted as tetrasomic, may segregation ratios which traploid ${ }^{3}$. Sainfoin (Onobrychis vicicefolia Sep is a tetraploid species with $2 n=28$ chromosomes compared with $2 n=14$ in 0 . Caputgalli Lam. ${ }^{4}$. The question arises whether it is an alfo- or an auto-tetraploid. This can best be settled by genetical tests based on the difference between tetrasomic and disomic
ratios, but the following observations seem sufficiently indicative to be worth reporting.

By colchicine treatment of seeds or seedlings, sainfoin plants have By colchicine treatment the normal number of chromosomes. They may be recognized by their pollen grains having nearly double the volume of those of normal plants. Abortion of seeds is characteristic of these plants, but occasional seeds have been obtained after open pollination in the presence of normal plants. These seeds give rise to 'triploid' progeny with 42 chromosomes. Other progeny with about 42 chromosomes have been raised from embryos dissected out of immature seeds and grown on nutrient agar until they form plants large enough to transplant to soil. 'Triploids' have a higher seed fertility than their maternal parent and have a surprisingly regular pollen, acetocarmine staining. The relative volumes of the regularly formed grains of $133 ; 182$.

The first metaphase of meiosis in the pollen mother cells of a plant with 40 chromosomes (obtained by culture of an embryo produced by open pollination of a doubled plant) was studied in a preparation made by a modification of Thomas's method ${ }^{5}$. The following conflgurations were seen in five cells which could be analysed completely : 1 trivalent, 18 bivalents and 1 univalent (in each of two cells); 4 trivalents and 14 bivalents; 3 trivalents, 15 bivalents and 1 univalent; 19 bivalents and 2 univalents. These associations show that normal sainfoin is either an autotetraploid or an allotetraploid of the Primula kewensis type, derived by chromosome doubling of a hybrid with a high degree of chromosome pairing. It is not an allotetraploid of the Raphanobrassica type, de
hybrid with little or no pairing.

Confirmatory evidence was obtained from an examination of meiosis in normal sainfoin, which was found to have a low chiasma frequency (about 14 per cell), forming mainly bivalents with a single chiasma, occasional bivalents with two chiasmata, chains of four chromosomes and univalents. The low chiasma frequency is probably an adaptive mechanism which assists regular disjunction by reducing the frequency of higher associations than bivalents.

Cambridge University Plant Breeding Institute.

J. L. FYFE Aug. 19.

${ }^{1}$ Müntzing, A., Hereditas, Lund, 23, 113 (1937), and Myers, W. M., J. Amer. Soc. Agron., 33, 893 (1941).

${ }^{2}$ Dawson, C. D. R., J. Genet., 42, 49 (1941). Neb. Agric. Exp. Sta., 124 (1942).

4 Senn, H. A., Bibliogr. Genet, 12, 175 (1938).

5 Thomas, P. T., Stain Tech., 15, 167 (1940).

\section{Perilobular Spaces in the Rabbit Pancreas}

Kühne and Lea in $1882^{1}$ described (but did not jllustrate), two kinds of lobule in the rabbit pancreas: $(a)$ a lobule smooth on the surface and in which the cell boundaries of the acinar cells cannot
be distinguished; $(b)$ a lobule irregular on the surface like a mulberry and in which the cell boundaries are quite distinct.

They were able to show that on the introduction of an injection mass into the pancreatic duct of the living rabbit it penetrated, even at the lowest injection pressures in the case of lobules of the $(b)$ type, by way of intercellular canaliculi into a space situated between the bases of the acinar cells and the membrana propria. Here the mass filled a series of clefts or spaces which made a triangular pattern on the surface of the lobule. Immediately the injection pressure was reduced the intercellular canaliculi closed again. In Iobules of the (a) type the mass never penetrated beyond the lumen of the alveoli. In the course of a recent re-examination of the blood supply of the rabbit pancreas a number of preparations were injected, immediately after death, and at a pressure never exceeding $120 \mathrm{~mm}$. mercury, with a carmine-gelatine mass, by way of the thoracic aorta. In these animals certain lobules stood out very distinctly by reason of the presence on the surface of the lobule of a network of sinusoidal-like spaces filled with the injection mass (Fig. 1). The arrangement of published by Kühne and Lea. The mulberry-like appearance of these published by Kuhne and Lea. The mulberry-like ap

A re-examination of specimens of uninjected rabbit pancreas showed A re-examination of specimens of uninjected rabbit pancreas showed
that no blood-containing spaces of this nature could be observed, but that occasional Jobules presented an apparent capsule of delicate

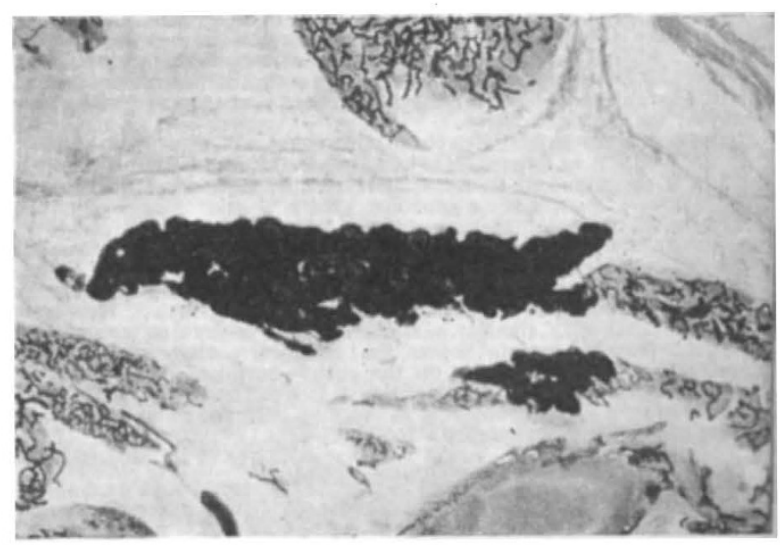

Fig. 1. Sectioned at $30 \mu$. ONe atypical lobUle sUrRotndeD BY SINUSOIDAI-LIKE SPACES FILLED WITH INJECTION MASS 